\title{
The speech ability on maxillary denture wearer: a systematic review
}

\author{
Meriyam Muchtar, ${ }^{*}$ Ike D. Habar
}

\section{Abstract}

Objective: Getting information about on influence of denture bases design on speech ability on maxillary denture wearer.

Methods: Electronic search in PubMed and Wiley online library databases to find articles that were published in last 20 years; between January 1998 to December 2017 with keywords "denture bases" and "speech". The articles were then selected by reviewing the title and abstract.
Result: The initial search obtained 52 articles. Then selected by involving the inclusion criteria. Finally, it gain 2 articles only that suitable with the inclusion criteria.

Conclusion: Speech ability is usually not the main complain of denture wearer. Subjects with inappropriate design of the prosthetic base, disposition of artificial teeth and functional quality (retention, support, stability) have dyslalia when pronunciation of separate phonemes is changed.

Keywords: Denture bases, Speech

Cite this Article: Muchtar M, Habar ID. 2018. The speech ability on maxillary denture wearer: a systematic review. Journal of Dentomaxillofacial Science 3(1): 1-4. D0I: 10.15562/jdmfs.v3i1.731

Department of Prosthodontic, Faculty of Dentistry, Hasanuddin University, Makassar, Indonesia
*Corresponding to:

Meriyam Muchtar, Department of Prosthodontic, Faculty of Dentistry, Hasanuddin University, Makassar, Indonesia

iyankmuchtar@gmail.com

Received: 27 January 2018

Revised: 19 March 2018

Accepted: 22 March 2018

Available online: 1 April 2018

\section{Introduction}

Human speech is a result of the following physiological processes: respiration, phonation, resonance, speech articulation, audition, neurological function, emotional behavior. ${ }^{1-3}$ The voice of each person is unique and is generally determined by the size of the resonator system (oral cavity, larynx, pharynx, vocal folds, nasal sinus), which vibrates at different frequencies, producing various sounds. ${ }^{1,4}$ The voice quality is characterized by speech intelligibility (relationship between the voice pitch, volume, timbre and speech speed). Changes in the oral cavity resulting from the loss of teeth and the resorption of the processus alveolaris maxillae or the processus alveo-laris mandibulae, may cause defects in the patient's voice and speech. One of the most frequent phonetic distortions is lisping ${ }^{5}$ Omission, substitution, distortion, addition and nasality are also possible when improper and functionally low quality dentures are used. ${ }^{5,6}$ Restrictions or alterations of the normal mandibular movement may impede the transmission of acoustic energy through the oral cavity, thereby affecting both oral resonatory characteristics and oral/nasal resonance balance. The phonetic adaptation of the patients with complete dentures depends on selection and placing of the artificial teeth, the thickness, size and placement of the maxillary prosthetic base, the optimal space of the tongue, individual adaptation capacity, patients sound recognizing capacity, Effective speech requires teeth. Proper positioning of the artifical teeth, appropriate design and functional quality of dental prostheses, small changes in the prosthetic field and full adaptation to the foreign body, the dental prosthesis in the oral cavity, are important factors speech intelligibility., ${ }^{2,45-9}$

The position of artificial teeth is a very important factor influencing the voice quality after the insertion of dental prostheses. It is proved (1 that the dental consonant /s/ is mispronounced phonetic articulators as tongue position and a narrow stream of air across the incisal edges. Therefore, this phoneme is often used for phonetic tests when the front artificial teeth are mounted. ${ }^{2,4,5}$

The anatomical orientators of the location of natural teeth is a very important factor when setting up the anterior teeth. Many authors believe that the incisal papilla and the rugae palatina are the most reliable orientators because resorption of the alveolar bone does not affect them. ${ }^{1,4,6}$

Resonance is one of the most important characteristics of the human speech. The resonance depends on the age, gender, spoken language, phonetic environment of the pronunced sounds, models and speech conventions. ${ }^{8,9}$

Tooth loss affects multiple parameters. In particular, prosthetic dentistry has put special emphasis on patient-centered assesments such as quality of life and satisfaction with dentures. Therefore, the outcome of dental rehabilitation is strongly influenced by the patients satisfaction with the 
dental situation in everyday life with oral function related such as the ability to properly articulate. ${ }^{9}$

\section{Methods}

This systematic review was written according to the guidelines of Preferred Reporting Items for Systematic reviews and Meta-Analyses (PRISMA) for reporting studies evaluating healthcare interventions. Population, Intervention, Control, Outcome question (PICO) of the present systematic review was: influence of denture bases design on speech ability on maxillary denture wearer.

Inclusion Criteria: articles in English, any research study published between January 1998 to December 2017, research on maxillary full denture wearer, research focused on patient with normal condition, comply the criteria in PICO questions, the author gets a full text journal, keywords used relate to temporomandibular disorders. Eksclusion criteria: all of which are not included in the inclusion criteria, journals that by systematic review method table 1.

\section{Results}

Search using the "denture bases" and "speech" keywords on pubmed and wiley search engines. As shown in figure 1, there are 52 journals in pubmed and 10 journals on wiley totaling 62 journals. After screning on title and abstract there are 10 journals with expected inclusion criteria and 52 journals with exclusion criteria. There are 5 relevant journals that do not have full text. finally the authors got 5 journals accordingly.

Table 1 The reviewed studies based on PICO-like structured reading

\begin{tabular}{lll}
\hline $\begin{array}{l}\text { No. } \\
\text { author, year } \\
\text { audy first }\end{array}$ & Population \\
\hline 1. & $\begin{array}{l}\text { Bortun } \\
\text { Cristina, }\end{array}$ & $\mathrm{n}=10$ \\
2004 & male $: 5$ \\
& female $: 5$ \\
& Two female patients \\
& had a low voice - \\
& after smoking and \\
& the other three had \\
& a normal voice for \\
& females.
\end{tabular}

2. F. Ztelzle, 2010

3. Giovanetti

$\mathrm{n}=6$

M, 2011 proms other th

\section{Intervention}

This research investigate none

patients with complete den-

tures and recorded

the vocal alterations caused

by position, size, various

materials (resin or ceramics)

of upper frontal artificial teeth. For the investigation researchers used the existent complete denture for the lower jaw. The vertical dimension

of occlusion from the old dentures was correct and therefore they maintained it in their study.

Comparasion

\section{Outcome}

Some patients had a remarkable adaptative capacity after repeating 5 - 6 keywords, mainly the females.

The acoustic alterations appeared in $70 \%$ of the cases of patients with ceramic teeth. A thin layer of impression material could be seen on palatogram in the zone of junction of oral facets of teeth with palatal plate and parallel with the line of first rugae palatine. This results from the crampons covering of ceramic teeth with resin.

The most obvious phonetic alteration visible on both spectrogram and palatogram appeared in the condition of oralized position of frontal upper teeth

Twenty-eight patients reading a standardized text were recorded twice - with and without their complete dentures in situ. A control group of 40 healthy subjects with natural dentition was recorded under the same conditions. Speech quality was evaluated by means of a poly- phone-based ASR according to the percentage of the word accuracy (WA).

40 German native speakers without speech disorders and no alter ation of the oral cavity or the dental arch, speaking the same local dialect as the patient group dental, psychological problems or any reported hearing impairment.
The WA of edentulous patients without complete dentures in situ was significantly reduced compared to the subjects with complete dental arches.

The WA improved to a significantly higher level by wearing complete dentures but did not reach that of the control group. Still, there was a significant difference. Ten of 28 complete dentures were found to be insufficient. That caused a lowering of the WA and showed significance compared to the WA of patients with sufficient complete dentures. Speaking with insufficient complete dentures turned out to produce an insignificantly higher WA than edentulous speech production

There are more several causes of misarticulation in complete denture wearer both male and female wearing prosthesis with a more palatal tooth position have more speaking difficulties as the dentures reduce the oral cavity volume.
A silicon key was used to none fixed the position of central incisor. This procedure enabled the anterior teeth to moved palatally, or closer to the crest of alveolar ridge. male : 3 
Table 1 Continued

\begin{tabular}{|c|c|c|c|c|c|}
\hline No. & $\begin{array}{l}\text { Study first } \\
\text { author, year }\end{array}$ & Population & Intervention & Comparasion & Outcome \\
\hline 4. & $\begin{array}{l}\text { Wafa'a } \\
\text { Radwan Al- } \\
\text { Magaleh, } \\
2012\end{array}$ & $\begin{array}{l}\mathrm{n}=30 \text { patients were } \\
\text { divided into } 3 \text { group. }\end{array}$ & $\begin{array}{l}\text { group II included } 10 \text { com- } \\
\text { pletely edentulous patients } \\
\text { with conventional den- } \\
\text { tures, and group III includ- } \\
\text { ed the same } 10 \text { edentulous } \\
\text { patients with neutral zone } \\
\text { dentures. }\end{array}$ & $\begin{array}{l}\text { Group } 1: \text { full } \\
\text { edentulous }\end{array}$ & $\begin{array}{l}\text { All patients, without exception, reported } \\
\text { being more comfortable with their NZ } \\
\text { dentures. For Al-Fateha recita- tion, there } \\
\text { were significant differences between both } \\
\text { denture groups and the control group } \\
\text { at immediate inser- tion. However, } 3 \text { weeks } \\
\text { later, there was still a significant difference } \\
\text { between groups I and II, while the difference } \\
\text { was statistically insignificant between groups } \\
\text { I and III. }\end{array}$ \\
\hline 5. & $\begin{array}{l}\text { Christian } \\
\text { Knipfer, } 2014\end{array}$ & $\mathrm{n}=28$ patients & $\begin{array}{l}\text { Speech was recorded in } \\
\text { patients } 1 \text { week prior to } \\
\text { fabrication of new complete } \\
\text { maxillary dentures and } 6 \\
\text { months thereafter }\end{array}$ & $\begin{array}{l}40 \text { subjects with mean } \\
\text { age } 59 \pm 12 \text { years } \\
\text { without any speech } \\
\text { disorders or oral dis- } \\
\text { eases and with a } \\
\text { complete maxilla an- } \\
\text { da mandible without } \\
\text { prosthetic treatment. }\end{array}$ & $\begin{array}{l}\text { Speech intelligibility improved significantly } \\
\text { after } 6 \text { months. Subject reported a signifi- } \\
\text { cantly higher OHRQoL (Oral Health-Related } \\
\text { Quality of Life) after maxillary rehabilitation } \\
\text { with complete dentures. }\end{array}$ \\
\hline
\end{tabular}
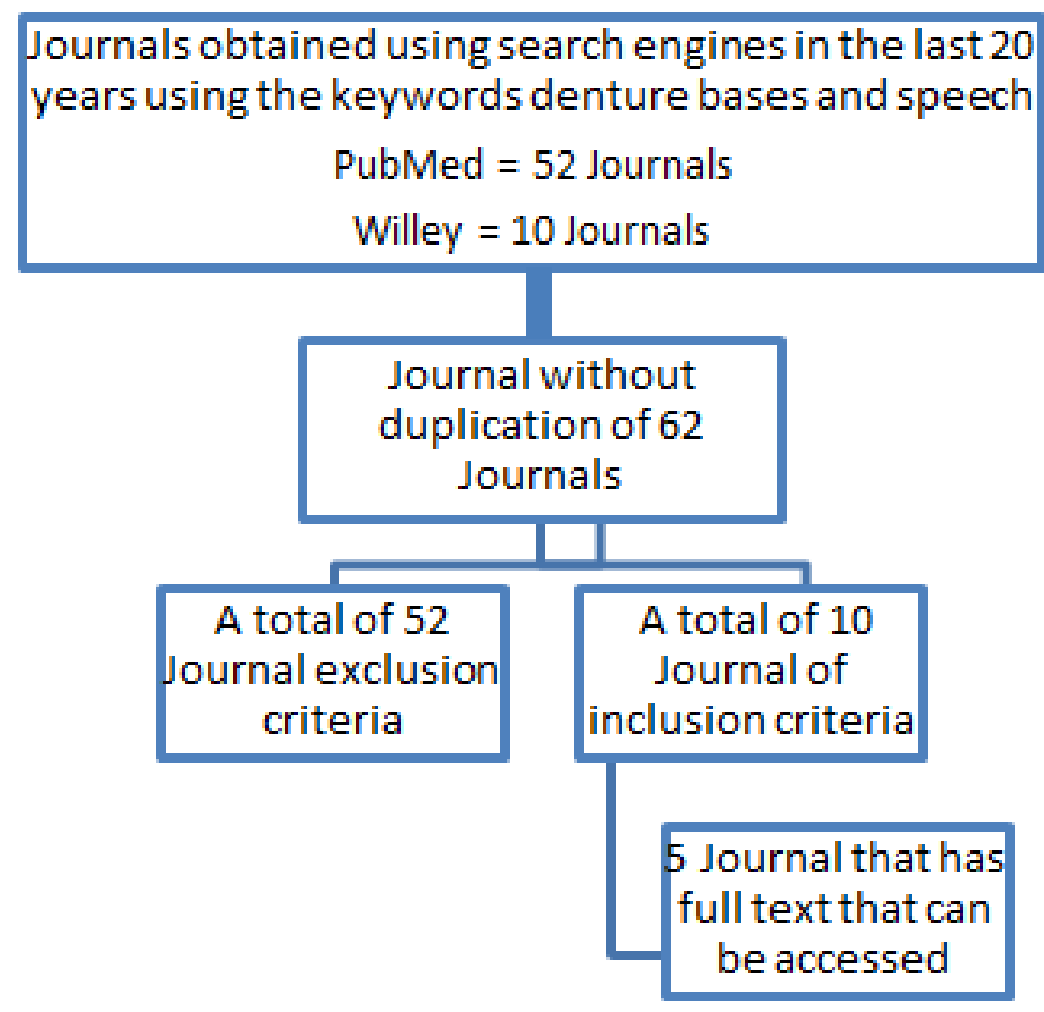

Figure 1 Article selection flow chart

The results of systemic analysis showed that of the 5 studies conducted, 3 studies (60 percent) of wich measure speech ability, 1 study (20 percent) that measure adaptive capacity, 1 study (20 percent) that measure patients satisfaction, showed in figure 2. Some patients had a remarkable adaptative capacity after repeating 5-6 keywords, mainly the females. Speech intelligibility improved significantly after 6 months.

The intervention used in studies by using complete denture is 3 studies ( 60 percent) and 2 studies (40 percent) by setting artificial teeth, showed in figure 3 . The acoustic alterations appeared in $70 \%$ of the cases of patients with ceramic teeth. The Word Accuracy (WA) improved to a significantly higher level by wearing complete dentures. There are more several causes of misarticulation in complete denture wearer both male and female wearing prosthesis with a more palatal tooth position have more speaking difficulties as the dentures reduce the oral cavity volume. Patients reported being more comfortable with Neutral Zone dentures.

\section{Discussion}

The basis of maxillary dentures is a very important component in the construction of dental prostheses. The basis of maxillary dentures provides stability of dentures and it is necessary for speech formation and intelligibility. The basis of maxillary dentures change articulation areas of phonemes in the oral cavity and may impair tongue movements. It is necessary to make dental prostheses as thin as possible for the right formation of phonemes and speech intelligibility. The thickness of the basis of maxillary dentures should be approximattely 1 , 4-2 $\mathrm{mm}$ in order to ensure good speech.

Subjects with inappropriate design of the prosthetic base, disposition of artifical teeth and functional quality (retention, support, stability) have dyslalia when pronunciation of separate 
adaptive capacity speech ability patient satisfaction

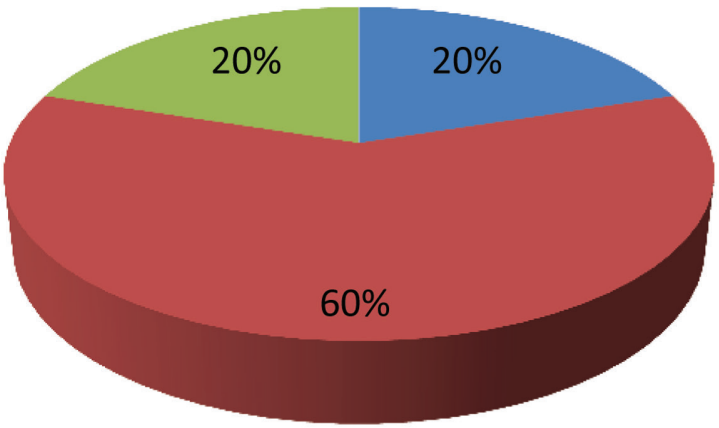

Figure 2 Measured in studies

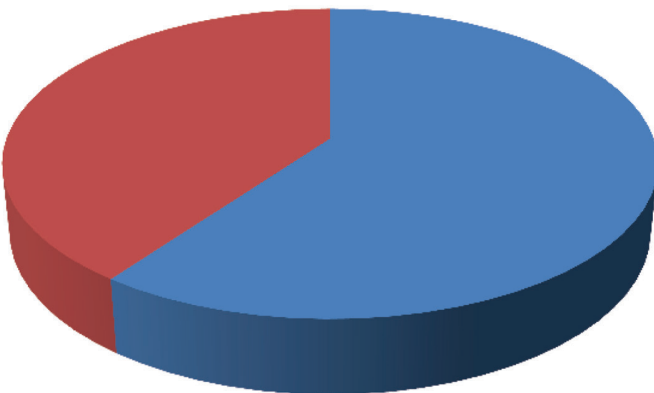

by using complete denture

by setting artificial teeth

Figure 3 Intervention used in reviewed studies

phonemes is changed. The most frequent articulation defects can be classified as omission, substitution, distortion, addition and lisping. If dentures are badly constructed and they are too loose, the tongue would compensate the lack of stability of dentures and thus, the speech intelligibility would decrease.

\section{Conclusion}

When designing removable dental prostheses it is important to evaluate the disposition of artifical teeth (taking into account phonetic pronunciation), and to make a phonetically beneficial construction of the base of dental prostheses. It is necessary to make the base of prostheses as thin as possible to improve good sound pronunciation, however it is important not to change the resistance ability of dentures.
Spectrograms and palatograms are suitable methods of investigation to evaluate phonetic quality of removable dental prostheses.

\section{Acknowledgment}

The author would like to thank the advisor for this paper who has been support author to do this review.

\section{Conflict of Interest}

The authors report no conflict of interest.

\section{References}

1. Balu K. Speech in prosthodontics, type of literature: commentary. JIADS 2011;2: 79-81.

2. Giovannetti M, Casucci A, Casucci D, et al. Phonetic analysis and maxillary anterior tooth position: a pilot study on preliminary outcomes. Int Dent SA 2011;5: 32-39.

3. Akbar FH, Anwar AI. The Correlation between denture usage satisfaction on quality life of the elderly. J Dentomaxillofac Sci 2017;2: 100-104.

4. Al-Magaleh WR, Swelem AA, Shohdi SS, et al. Setting up of teeth in the neutral zone and its effecton speech. Saudi Dent J 2011;24: 43-48.

5. Ozbeki M, Tulunoglu I, Ozkan S, et al. Evaluation of articulation of Turkish phonemes after removable partial denture application. Braz Dent J 2003;14: 125-131.

6. Scarsellone JM, Rochet AP, Wolfaardt JF. The influence of dentures on nasalance values in speech. Cleft PalateCraniofac J 1999;36: 51-56.

7. Bortun C, Leretter M, Sandu L, et al. Phonetic evaluation of the edentulous patient correlated with the various settings of the artificial teeth. Serb Dent J 2004;51: 93-99.

8. Stelzle F, Ugrinovic B, Knipfer C, et al. Automatic,computerbased speech assessment on edentulous patients with and without complete dentures preliminary results. J Oral Rehabil 2010;37: 209-216.

9. Knipfer C, Rieman M, Bocklet T, et al. Speech intelligibity enhancement after maxillary denture treatment and its impact on quality of life. Int J Prosthodontics 2014:27: 61-69.

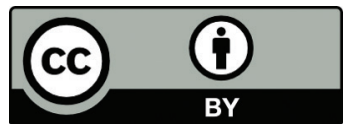

This work is licensed under a Creative Commons Attribution 